Original Paper http://ajol.info/index.php/ijbcs http://indexmedicus.afro.who.int

\title{
Performance de l'association mixte sorgho-niébé sur les productivités du sorgho et des sols en zone Soudano-Sahélienne du Burkina Faso
}

\author{
Koulibi Fidèle ZONGO ${ }^{1,3 *}$, Edmond $\mathrm{HIEN}^{2,3}$, Boussa Tockville MARE ${ }^{2}$ and \\ Daouda GUEBRE ${ }^{2,3}$
}

\author{
${ }^{1}$ Centre Universitaire de Tenkodogo, Université Thomas Sankara, 12 BP 417, Ouagadougou 12, \\ Burkina Faso. \\ ${ }^{2}$ Université Joseph KI-ZERBO, Unité de Formation et de Recherche en Science de la Vie et de la Terre \\ (UFR/SVT), 03 BP 7021, Ouagadougou 03, Burkina Faso. \\ ${ }^{3}$ LMI-IESOL, Ouagadougou, Burkina Faso. \\ *Auteur correspondant ; E-mail: fidelezongo62@gmail.com ; Tel. : +226 65106110
}

\begin{tabular}{ccc}
\hline Received: 09-12-2020 & Accepted: 28-05-2021 & Published: 30-07-2021 \\
\hline
\end{tabular}

\section{RESUME}

Dans la zone soudano-sahélienne du Burkina Faso, la performance des associations mixtes sorgho-niébé reste faible bien que les nombreux services écosystémiques rendus par les associations céréales-légumineuses soient connus. L'objectif de la présente étude a été de comprendre la performance des associations mixtes sorghoniébé sur la productivité du sorgho et du sol. L'étude a consisté à conduire des tests multi-locaux avec de petits agriculteurs familiaux de la région Nord du Burkina Faso. Des traitements à base de zaï simple (ZS), zaï $+9 \mathrm{t}^{\mathrm{t}}$ ${ }^{1}$ de substrats organiques $(\mathrm{ZF})$ et zaï $+9 \mathrm{t} \mathrm{ha}^{-1}$ de substrats organiques $+50 \mathrm{~kg} \mathrm{ha}^{-1}$ d'urée $(\mathrm{ZFN})$ ont été testés en 2013, chaque traitement étant répété 9 fois. En 2014, le traitement ZFN a été remplacé par le traitement zaï +9 t $\mathrm{ha}^{-1}$ de substrat organique $+600 \mathrm{~kg} \mathrm{ha}^{-1}$ de Burkina Phosphate (ZFP). Chaque parcelle élémentaire a abrité l'association mixte sorgho-niébé et la monoculture du sorgho. Les résultats ont montré que l'association mixte sorgho-niébé a généralement entrainé une dépréciation des rendements du sorgho par rapport à la monoculture du sorgho. Par contre, une performance significative de $+58 \%$ en 2014 et un accroissement de $+10 \%$ en 2013 des rendements totaux grains de sorgho et de niébé ont été enregistrés par rapport à la monoculture du sorgho. Une grande efficacité d'acquisition des nutriments par le sorgho associé au niébé a été enregistrée en comparaison à la monoculture du sorgho. Pour une meilleure performance des cultures mixtes sorgho-niébé, les traitements $\mathrm{ZS}$ et $\mathrm{ZF}$ sont à recommander pour augmenter les rendements totaux grains de niébé et de sorgho ainsi que l'acquisition de $\mathrm{N}$ dans les grains du sorgho ; les traitements ZFN et ZFP sont, quant à eux, sont à recommander pour améliorer la fertilité résiduelle en $\mathrm{N}$ et $\mathrm{P}$ des sols dans la région Nord du Burkina Faso.

(C) 2021 International Formulae Group. All rights reserved.

Mots clés : Performance, culture mixte sorgho-niébé, rendements, fertilité résiduelle.

\section{Performance of sorghum-cowpea mixed cropping system on sorghum and soils productivities in the Sudano-Sahelian zone of Burkina Faso}

\begin{abstract}
In Sudano-Sahelian zone of Burkina Faso, the performance of sorghum and cowpea mixed cropping system remains low although the many ecosystems provided associated by cereal and legume mixed or
\end{abstract}


intercropping system are known. The objective of this study was to understand the performance of these sorghum and cowpea mixed cropping system on the productivities of sorghum and soils. The study consisted to multilocal tests with small family farmers in the northern region of Burkina Faso. Treatments based on simple zaï (ZS), zaï $+9 \mathrm{t} \mathrm{ha}^{-1}$ of organic substrates (ZF) and zaï $+9 \mathrm{t} \mathrm{ha}^{-1}$ of organic substrates $+50 \mathrm{~kg} \mathrm{ha}^{-1}$ of urea (ZFN) were tested in 2013, each treatment being replicated at 9 times. In 2014, the ZFN treatment was replaced by the zaï $+9 \mathrm{t} \mathrm{ha}^{-1}$ of organic substrate $+600 \mathrm{~kg} \mathrm{ha}^{-1}$ of Burkina Phosphate (ZFP). Each elementary plot was occupied by sorghum and cowpea mixed cropping system and monocropping sorghum. The results showed that the yields of sorghum mixed by cowpea generally lowered than the yields of monocropping sorghum. In contrast, a significant performance of $+58 \%$ in 2014 and an increase of $+10 \%$ in 2013 on total sorghum and cowpea grains yields were recorded compared to monocropping sorghum. The high efficiency of nutrient acquisition by sorghum in mixed cropping system with cowpea was recorded compared to monocropping sorghum. For better performance of sorghum and cowpea mixed cropping system, ZS and ZF treatments are recommended to increase total sorghum and cowpea grains yields, the $\mathrm{N}$ acquisition in sorghum grains, and ZFN and ZFP treatments were suggested to improve residual $\mathrm{N}$ and $\mathrm{P}$ fertility of soils in the northern region Burkina Faso.

(C) 2021 International Formulae Group. All rights reserved.

Keywords: Performance, sorghum-cowpea mixed cropping system, yields, residual fertility.

\section{INTRODUCTION}

Dans la zone soudano-sahélienne d'Afrique de l'Ouest, les associations vivrières sorgho-niébé ou mil-niébé sont fréquentes et occupent plus de la moitié des superficies cultivées dans les systèmes de culture de la plupart des exploitations agricoles familiales. $\mathrm{Au}$ Burkina Faso, ces associations couvrent annuellement plus de $93 \%$ des superficies emblavées dans cette zone (Ouédraogo, 2005 ; Zongo et al., 2016). Il convient de noter que le sorgho et le mil constituent $85 \%$ de l'alimentation de base des populations dans ladite zone (FAO, 2009). Dans ces systèmes de production, le sorgho ou le mil ne bénéficie de l'azote fixé par le niébé que s'il y est associé car les résidus de culture sont exportés des champs et vont prioritairement à l'alimentation animale et non à la fabrication de matières fertilisantes pour restaurer ou compenser la fertilité des sols. Bationo et al. (1998) avaient évalué le déficit en éléments nutritifs dans ces systèmes

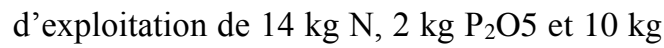
$\mathrm{K}_{2} \mathrm{O}$ par ha. Ce faisant, la fertilité des sols est sévèrement compromise occasionnant de faibles rendements et conduisant à une insécurité alimentaire des ménages notamment ruraux. Maintenir, voire augmenter la fertilité des sols en ces éléments essentiels devient alors un impératif pour améliorer leur productivité et les rendements des cultures. A ce titre, les associations mixtes sorgho-niébé à travers les services ecophysiologiques et écosystémiques rendus par le niébé, peuvent être judicieusement utilisés comme une alternative à l'amélioration des rendements et de la productivité des sols. La preuve est que le niébé associé ou non à des céréales peut fixer jusqu'à $134 \mathrm{~kg} \mathrm{~N} \mathrm{ha}^{-1}$ et $52 \mathrm{~kg} \mathrm{~N}$ ha $^{-1}$ de l'azote atmosphérique selon respectivement Dakora et al. (1987) et Egbe et Egbo (2011). Du fait de cette fixation, les pools d'azote et de phosphore de la rhizosphère peuvent s'enrichir et améliorer la disponibilité en ces éléments minéraux pour les cultures. Ces éléments minéraux peuvent être transférés directement à la céréale associée en année de culture grâce au turnover racinaire et aux ponts micorhyziens, ou de manière résiduelle en année subséquente (Mayer et al., 2003 ; Xiao et al., 2004 ; Bado et al., 2006; Wichern et al., 2008; Rahman et al., 2009 ; Fustec et al., 2010, 2011). Ces transferts proviennent de la rhizodéposition d'exsudats, de mucilages et de produits issus de la desquamation des cellules racinaires, de la sénescence des racines et des nodules de la légumineuse à travers un processus de minéralisation par les microorganismes du sol (Wichern et al., 2008; Fustec et al., 2010). Ainsi, 10 à $20 \%$ de l'azote de la légumineuse peuvent être transférés à la céréale (Fustec et Corre-Hellou, 2009; Laberge et al., 2011). Aussi, l'acidification du sol rhizosphérique de la légumineuse suite à une excrétion de protons 
$\mathrm{H}_{3} \mathrm{O}^{+}$en réponse à son activité fixatrice d'azote (Cu et al., 2005; Li et al., 2008 ; Latiti, 2016) aboutit à une augmentation du pool de phosphore organique pouvant conduire à sa phyto disponibilité. Par ailleurs, les grands avantages de la culture associée par rapport à la culture unique pourraient probablement être attribués à l'augmentation de l'utilisation complémentaire des ressources de croissance (Aminifar et Ghambari, 2014; Duvvada et Maitra, 2020) comme l'azote et la lumière dans l'espace et dans le temps (Liu et al., 2017 ; Legwaila et al., 2019; Duvvada et Maitra, 2020).

Fort de ces constats et compte tenu de l'importance du sorgho dans l'alimentation en zone soudano-sahélienne du Burkina Faso, il est nécessaire de partir des pratiques locales afin de proposer des pratiques culturales spécifiques et raisonnées améliorant la fertilité du sol et les rendements du sorgho associé au niébé. Il s'est agi dans cette étude, d'apprécier les performances en termes d'effets de résultats des associations sorgho-niébé sur les rendements, l'acquisition des nutriments du sorgho et la fertilité résiduelle des sols en zone soudano soudano-sahélienne du Burkina Faso.

\section{MATERIEL ET METHODES}

\section{Caractéristiques de la zone et des sites d'études}

L'étude a été conduite durant 2 ans (2013 et 2014) dans la région Nord du Burkina Faso. Les villages de Pougyango dans la province du Passoré $\left(12^{\circ} 58^{\circ} \mathrm{N}, 2^{\circ} 08^{\prime} \mathrm{O}\right)$, de Zindiguéssé dans le Zandoma $\left(13^{\circ} 16^{\prime} \mathrm{N}\right.$, $2^{\circ} 20^{\prime}$ O) et de Soumyaga dans le Yatenga $\left(13^{\circ} 30^{\prime} \mathrm{N}, 2^{\circ} 24^{\prime} \mathrm{O}\right)$ ont été choisis pour mener cette étude (Figure 1). Ces villages ont été choisis car ils sont proches sur les plans pédoclimatiques et topographiques. Le climat est de type soudano-sahélien avec une courte saison pluvieuse allant de juin à septembre où se concentre $90 \%$ de la pluviométrie annuelle. Sur la période 2000-2014, la pluviométrie moyenne annuelle a varié dans les gammes de 500 à $900 \mathrm{~mm} \mathrm{an}^{-1}$ avec une moyenne de 715,5 $\mathrm{mm} \mathrm{an}^{-1}$ (Figure 2). Le cumul pluviométrique a été d'environ 20\% inférieure en 2013 par rapport à 2014. Les températures moyennes mensuelles les plus élevées sont de $35^{\circ} \mathrm{C}$ et les plus faibles de $24{ }^{\circ} \mathrm{C}$.

Les sols de la région peuvent être regroupés en 3 grands types à savoir les plinthosols épipétriques, les lixisols épi ou endo pétroplinthiques et les lixisols hypogleyiques ferriques (FAO, 2014). Ce sont principalement des sols peu évolués présentant un profil peu différencié avec une profondeur utile moyenne est d'environ $40 \mathrm{~cm}$. La couche exploitable par les racines repose souvent sur une carapace ou une cuirasse ferrugineuse. Ces sols sont soumis à une forte érosion hydrique en raison de leur position physiographique et de l'absence de couvert végétal. Les propriétés physiques, sont marquées par une charge graveleuse importante et une texture souvent sablo-limoneuse en surface à linono-argileuse voire argilo-limoneuse en profondeur. Sur le plan chimique, ces sols présentent un $\mathrm{pH}$ acide avec des teneurs moyennes en matière organique d'environ $0,3 \%$ (FAO, 2000). La végétation naturelle est formée de steppes, de brousses tigrées, de savanes arbustives et arborées (Guinko, 1998).

\section{Dispositif expérimental}

Un dispositif expérimental composé de 3 micro parcelles élémentaires de $25 \mathrm{~m}^{2}$ (5 m $\mathrm{X} 5 \mathrm{~m}$ ) et répété 9 fois, à raison de 3 par village, a été mis en place et conduit de manière participative avec les petits agriculteurs de la région Nord du Burkina Faso. Des substrats organiques localement produits ont été utilisés en se conformant aux pratiques usuelles de production des associations mixtes sorghoniébé. Ces dispositifs sont des tests multilocaux et ont été considérés comme des blocs éclatés. Chaque test multi-local a été placé dans la partie médiane des champs des agriculteurs. Les champs où les tests ont été conduits sont caractérisés par une homogénéité pédogénétique. Il s'agit majoritairement de lixisols endo-pétroplinthiques (WRB, 2014). Le pourtour de chaque parcelle élémentaire de chaque test était séparé par une allée de $2 \mathrm{~m}$. 
Les champs où les tests ont été installés étaient délimités en amont et/ou en aval par des cordons pierreux. Les précédents culturaux des 5 années précédentes les tests dans tous les champs utilisés sont des associations sorghoniébé.

\section{Traitements}

Les traitements appliqués sur chaque parcelle élémentaire en 2013 ont été : ZS = Zaï simple sans aucun apport ; ZF $=\mathrm{Zaï}+9 \mathrm{t} \mathrm{ha}^{-1}$ de substrats organiques et ZFN $=$ Zaï $+9 \mathrm{tha}^{-1}$ de substrats organiques $+50 \mathrm{~kg} \mathrm{ha}^{-1}$ d'urée. En 2014, le traitement ZFN a été substitué par $\mathrm{ZFP}=$ Zaï $+9 \mathrm{tha}^{-1}$ de substrats organiques + $600 \mathrm{~g} \mathrm{ha}^{-1}$ de Burkina Phosphate. Les substrats organiques utilisés étaient composés d'un mélange de résidus de paille ayant servi d'aliments pour le bétail, de fèces d'animaux, d'ordures ménagères conformément aux pratiques des petits agriculteurs de la zone. Dans chaque village, ces substrats ont été annuellement collectés dans des fosses pendant la saison sèche allant de novembre à mai. Les substrats épandus dans les parcelles des tests sont des composites obtenus en mélangeant les substrats collectés dans chaque village. Le Burkina phosphate (BP) provient de phosphate naturel de Kodjari finement broyé. L'urée utilisée était à $46 \% \mathrm{~N}$. Les caractéristiques des substrats et du BP par village sont consignées dans le Tableau 1.

\section{Conduite des tests}

Durant les 2 années d'observations, les opérations culturales ont d'abord consisté au creusage manuel du zaï sur chaque parcelle élémentaire, durant la première quinzaine $\mathrm{du}$ mois de juin. La technique du zaï permet de mieux concentrer, localement sur les parcelles, les eaux de pluie et les substrats appliqués. Les poquets de zaï de $20 \mathrm{~cm}$ de diamètre et de profondeur ont été creusés suivant un rayonnage croisé de $0,80 \mathrm{~m}$ entre les lignes et $0,40 \mathrm{~m}$ entre les poquets d'une même ligne. Les lignes de poquets étaient perpendiculaires à la pente; Soixante-dix-sept (77) poquets de zaï ont été creusés par parcelle élémentaire. Dans chaque poquet de zaï, $300 \mathrm{~g}$ de substrats organiques ont été ensuite apportés en une seule fois avant semis. Cette dose correspond à celle usuellement apportée par les petits agriculteurs de la région. Elle correspond à la poignée de main d'un adulte de plus de 25 ans. Le mode de culture a consisté à scinder verticalement chaque parcelle élémentaire en 2 parties dans le sens de la pente. Une première partie a abrité une monoculture de sorgho (Sorghum bicolor (L.)) var. «Kapelga». La seconde partie a été emblavée en association mixte sorgho-niébé; La variété de niébé utilisée est Vigna unguiculata (L.) Walp. var. " $K V X$ 396-4-5-2D ». C'est une variété à port semi-érigé. Le cycle semis-maturité de la variété de sorgho est compris entre 90 et 110 avec un rendement grain moyen de 1 à $1,5 \mathrm{t}$ ha1. La variété du niébé a un cycle de 70 jours avec un rendement moyen grain de $1,5 \mathrm{t} \mathrm{ha}^{-1}$ en station et $0,8 \mathrm{tha}^{-1}$ en milieu paysan. Le choix de ces variétés découle du fait qu'elles soient couramment utilisées par les petits agriculteurs de la région. Ces variétés résistantes à la sécheresse sont bien adaptées à notre zone d'étude car leurs aires de culture se situent entre les isohyètes 400 et $800 \mathrm{~mm}$. De plus, elles sont vulgarisées dans la région en raison de leurs potentialités agronomiques. Quelle que soit l'année d'observation, dans le cas de l'association, le niébé et le sorgho ont été semés en même temps, dans le même poquet, à la dernière semaine du mois de juin. Le démariage-repiquage a consisté à laisser 2 plants de sorgho par poquet quel que soit le mode de culture et 2 plants de niébé dans les associations mixtes sorgho-niébé. Deux désherbages ont été effectués par année de culture. La dose d'urée a été de 1,6 g poquet $^{-1}$, apportée en une seule fois, de manière localisée puis enfouis. Le BP a été apporté directement avec les substrats organiques à la dose de $20 \mathrm{~g}$ poquet $^{-1}$.

\section{Evaluation des rendements du niébé et du sorgho}

En 2013 comme en 2014, deux carrés de rendement de $3,2 \mathrm{~m}^{2}(0,8 \mathrm{~m} \mathrm{x} 4 \mathrm{~m})$ renfermant 
10 poquets de zaï ont été placé dans la partie médiane selon que le sorgho soit associé au niébé ou non et en fonction des traitements. Les pailles et épis de sorgho ainsi que les gousses de niébé ont été récoltées, séchées jusqu'à poids constant et pesées. Les rendements moyens en paille du sorgho ainsi que les rendements moyens grains en $\mathrm{tha}^{-1}$ du niébé et du sorgho par traitement ont été également déterminés. Les poids de 1000 grains du sorgho ont été aussi évalués.

\section{Prélèvement et analyses chimiques des échantillons}

Les analyses chimiques ont concerné les échantillons de plantes de sorgho et de sols prélevés à la récolte en 2013 et 2014 . Au total et par année, 54 échantillons de grains de sorgho broyés à $2 \mathrm{~mm} \quad(27$ échantillons/traitement $\times 2$ modes de culture) ont été obtenus. Des échantillons composites de sols (27 échantillons/traitement $\times 2$ modes de culture soit 54 au total) ont été obtenus par mélange des échantillons élémentaires prélevés dans les poquets de zaï dans la couche $0-30 \mathrm{~cm}$ au moment de la récolte du sorgho. Ces échantillons ont été d'abord tamisés à $2 \mathrm{~mm}$ puis broyés à $200 \mu \mathrm{m}$ pour les analyses. Les teneurs en azote et phosphore totaux des échantillons de plantes et de sols ont été déterminés. L'azote $(\mathrm{N})$ en $\mathrm{mg} \mathrm{g}^{-1}$ des échantillons de plantes et de sols a été déterminé par la méthode $\mathrm{CHN}$ avec le microanalyseur NA-2000. Les Phosphores totaux (P) en $\mathrm{mg} \mathrm{g}^{-1}$ des plantes ont été déterminés par la méthode de Kitson et Mellon (1944). Les quantités acquises de $\mathrm{N}$ et de $\mathrm{P}$ des grains de sorgho ont été déduites en multipliant la teneur de chacun de ces éléments par les poids des grains en fonction des traitements et des modes de cultures. Les Phosphores totaux (P) des sols ont été dosés selon la méthode Olsen-Dabin (Olsen et al., 1954 modifié Dabin, 1967).

\section{Analyses statistiques}

Les tableaux et les figures ont été réalisés avec le logiciel Excel 2010. Les analyses statistiques des données à la récolte ont été effectuées par le logiciel $\mathrm{R}$ version 2.14 .1 (2011) et l'interface graphique $\mathrm{R}$ Commander au seuil de $\mathrm{p}<0,05$. Les procédures de comparaison des moyennes utilisées ont été l'analyse de la variance (ANOVA). Les comparaisons des moyennes et le calcul des significativités ont été effectuées par le test de Tukey HSD $(\mathrm{p}<0,05)$. Le test de Shapiro wilk au seuil de 5\% a été utilisé pour vérifier la normalité des données avant toute analyse.

Pour évaluer les performances (effets de résultats) de l'association sur la productivité du sorgho et la fertilité des sols, l'approche suivante a été appliquée : les rendements moyens du sorgho associé au niébé ainsi que les rendements totaux grains de sorgho et de niébé (la somme des rendements grains de sorgho et de niébé en culture associée) ont été séparément comparés aux rendements moyens de la monoculture du sorgho selon l'analyse des variances ANOVA. Les comparaisons des teneurs moyennes des sols en $\mathrm{N}$ et $\mathrm{P}$ totaux des sols en fonction de l'année, des modes de culture, des traitements ont été aussi effectuées. La performance de l'association sorgho-niébé a été également mesurée à travers l'efficacité d'acquisition des nutriments $\mathrm{N}$ et $\mathrm{P}$ se traduisant par les valeurs des pentes des droites de régression linéaire de Pearson réalisées entre les paramètres de rendements du sorgho et les teneurs en $\mathrm{N}$ et $\mathrm{P}$ des plantes et des sols. Le Taux de Surface Equivalente (land equivalent ratio : LER) qui se définit comme la superficie qu'une monoculture doit occuper pour produire la même quantité que sa composante en cultures mixte ou intercalaire (Willey, 1979; Mead et Willey, 1980) a été aussi calculé pour le sorgho. En effet, si la valeur de LER partiel est supérieure à 1 , cela signifie que l'association l'emporte sur les cultures pures au point de vue rendement car on est dans des associations additives dont les densités relatives de sorgho associé au niébé sont de même niveau que les densités de la monoculture du sorgho. 
K. F. ZONGO et al. / Int. J. Biol. Chem. Sci. 15(3): 987-1005, 2021

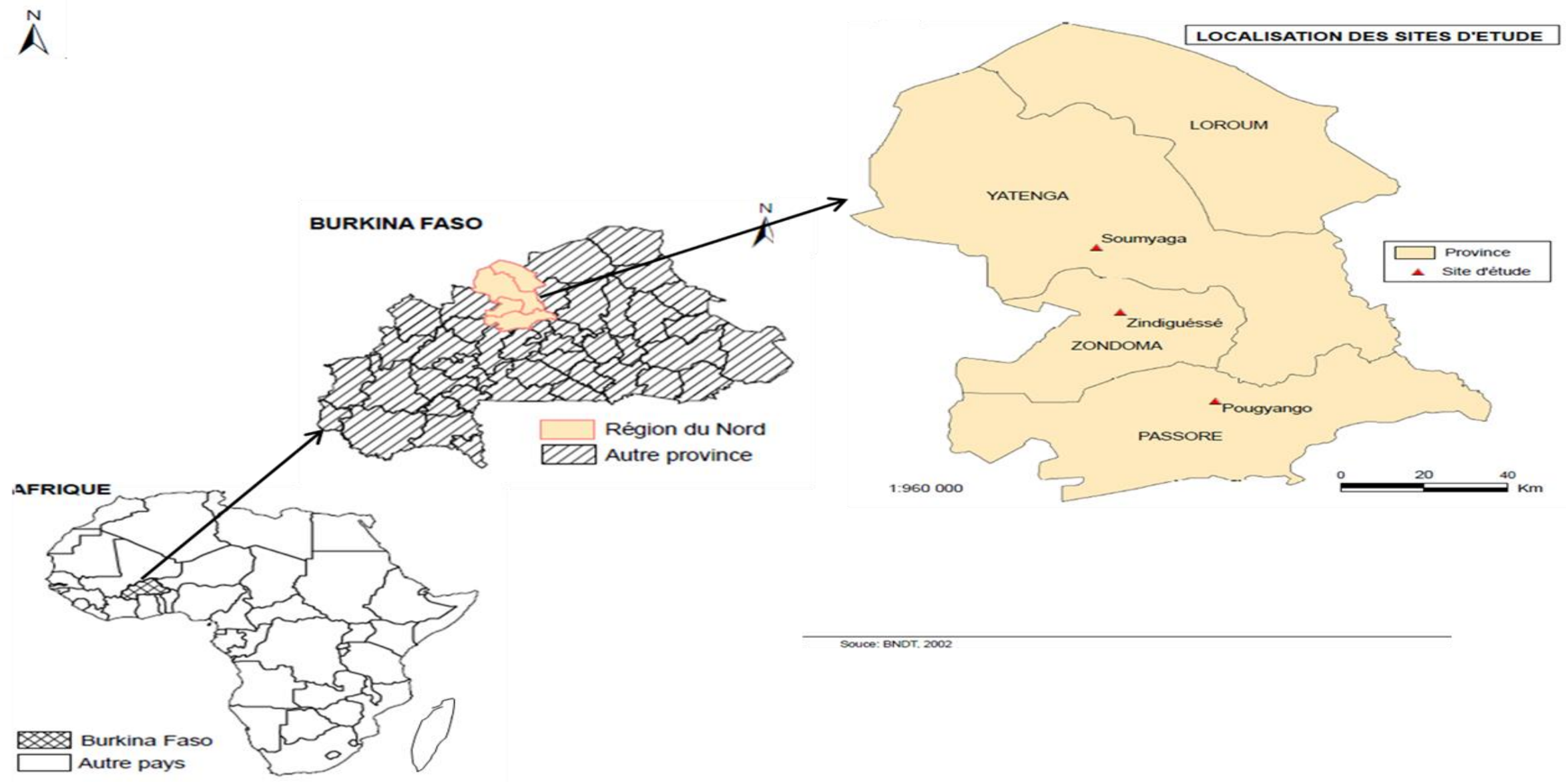

Figure 1 : Localisation de la région du Nord du Burkina Faso et des villages ou sites d'étude (Zongo et al., 2016). 


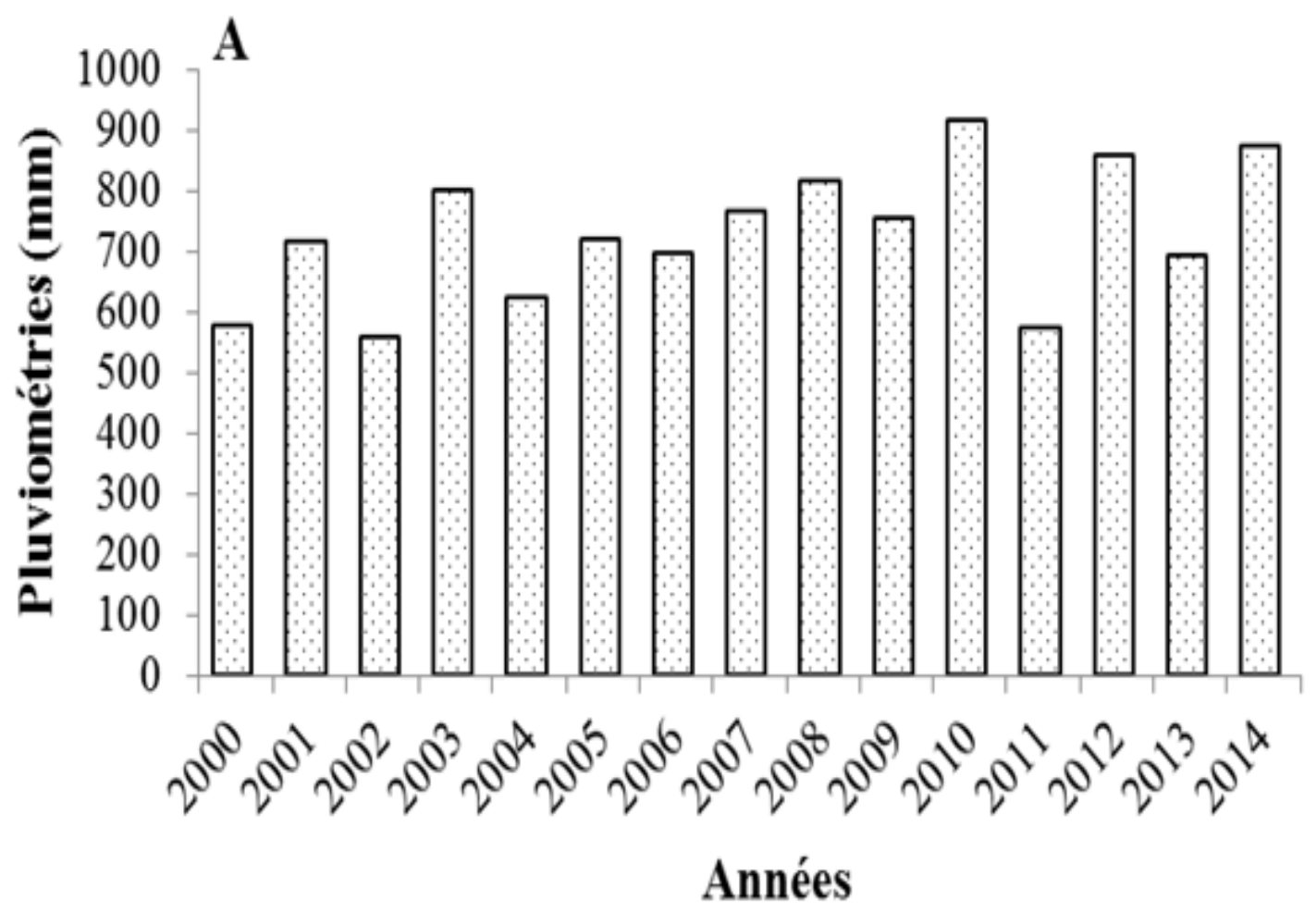

Figure 2 : Pluviométrie de la zone d'étude de 2000 à 2014.

Tableau 1 : Caractéristiques des substrats organiques.

\begin{tabular}{lcc}
\hline $\begin{array}{l}\text { Caractéristiques des } \\
\text { substrats organiques }\end{array}$ & $\mathbf{2 0 1 3}$ & $\mathbf{2 0 1 4}$ \\
\hline Humidité (\%) & 10 & 44 \\
Fractions fines (\%) & 78,40 & 77,23 \\
Refus végétaux (\%) & 1,03 & 1,10 \\
Refus minéraux (\%) & 20,57 & 21,67 \\
$\mathrm{C}\left(\mathrm{mg} \mathrm{g}^{-1}\right)$ & 477,53 & 111,17 \\
$\mathrm{~N}\left(\mathrm{mg} \mathrm{g}^{-1}\right)$ & 28,13 & 10,93 \\
$\mathrm{Ratio} \mathrm{C} / \mathrm{N}$ & 17,33 & 10,13 \\
$\mathrm{P}\left(\mathrm{mg} \mathrm{g}^{-1}\right)$ & 1,83 & 1,67 \\
\hline \multicolumn{2}{c}{$\mathrm{C}=$ Carbone total ; N= azote total ; P= Phosphore total. }
\end{tabular}




\section{RESULTATS \\ Effet de l'association mixte sorgho-niébé sur les rendements du sorgho}

Le Tableau 2 présente les effets globaux de l'association sorgho-niébé sur les rendements et les quantités en $\mathrm{N}$ et $\mathrm{P}$ des grains du sorgho. Les effets globaux de l'association sorgho-niébé sur les rendements grains du sorgho ont été généralement négatifs par rapport à la monoculture du sorgho. Indépendamment de l'année de culture, l'association sorgho-niébé a globalement impacté de manière significative de $+27 \%$ les rendements totaux grains de sorgho et de niébé comparativement à la monoculture du sorgho $(p=0,04)$. En 2013, des augmentations de 10\% des rendements totaux grains de sorgho et de niébé et de $23 \%$ des quantités de $\mathrm{N}$ des grains de sorgho ont été constatées par rapport à ces rendements respectifs en monoculture du sorgho. En 2014, les rendements totaux grains du sorgho et de niébé ont été significativement affectés de $+58 \%$ comparativement à la monoculture du sorgho.

Le Tableau 3 présente les effets de l'association sorgho-niébé sur les rendements du sorgho en fonction de l'année de culture et des traitements. En 2013, aucune différence significative n'a été observée sur les rendements du sorgho associé au niébé comparé aux rendements en monoculture du sorgho (Tableau 3). Cependant, les rendements totaux grains de sorgho et de niébé ont été augmentés de $1 \%$ sous ZS, de $22 \%$ sous ZF et de $5 \%$ sous $\mathrm{ZFN}$; et les quantités en $\mathrm{N}$ des grains de sorgho associé au niébé ont augmenté de 27,23 et $22 \%$ respectivement sous les traitements ZS, ZF et ZFN comparativement à la monoculture du sorgho sous ces mêmes traitements. En 2014, les traitements ZS et ZF ont significativement et respectivement affectés de $+84(\mathrm{p}=0,01)$ et $+59 \%(\mathrm{p}=0,005)$ les rendements totaux grains de sorgho et de niébé par rapport à la monoculture du sorgho (Tableau 3). Les rendements totaux grains de sorgho et de niébé ont aussi été positivement affectés de 35\% sous ZFP en 2014 par rapport à ceux obtenus en monoculture du sorgho. Les rendements en pailles, les quantités en $\mathrm{N}$ et $\mathrm{P}$ des grains sous sorgho associé au niébé par rapport à ceux obtenus sous sorgho en monoculture ont été significativement mais négativement affectés sous les traitements ZFP en 2014. Au cours des 2 années, quel que soit le mode de culture et le traitement, les quantités en $\mathrm{P}$ des grains du sorgho associé au niébé ont été faibles comparativement à celles sous sorgho en monoculture.

\section{Land Equivalent Ratio (LER) partiel du sorgho}

Le Tableau 4 présente les Land Equivalent Ratio (LER) partiels du sorgho associé au niébé par rapport au sorgho en culture pure. Indépendamment de l'année de culture, les LER partiels des rendements en pailles et en grains du sorgho associé au niébé par rapport à la monoculture du sorgho ont été respectivement égale à 0,77 et 0,73 . En 2013, ces LER des rendements en pailles sorgho associé au niébé comparé au sorgho en monoculture ont été de 0,88 pour les rendements en pailles et de 0,83 pour les rendements grains. En fonction des traitements durant cette même année, les LER partiels du sorgho associé au niébé par rapport à ceux sous sorgho en monoculture ont été de 0,74 sous ZS ; 0,83 sous ZF et de 0,99 sous ZFN pour les rendements en pailles. Pour les rendements en grains, ils ont été de l'ordre de 0,73 sous ZS, 0,93 sous ZF et de 0,82 sous ZFN. En 2014, par contre, les LER partiels des rendements en pailles et en grains du sorgho associé au niébé comparé à ces rendements du sorgho en monoculture ont été inférieurs à 0,5 quel que soit le mode de culture ou le traitement.

\section{Effet de l'association mixte sorgho-niébé sur les paramètres $\mathbf{N}$ et $\mathbf{P}$ des sols}

Dans les Tableaux 5 et 6 , en fonction du mode de culture, de l'année, des traitements et des interactions, aucune différence significative et positive n'a été enregistrée entre les teneurs $\mathrm{N}$ et $\mathrm{P}$ des sols sous sorgho associé au niébé comparativement à la monoculture du sorgho. Cependant, en 
fonction du mode de culture, les teneurs en $\mathrm{N}$ des sols ont été globalement augmentées de $10 \%$ sous sorgho associé au niébé par rapport aux sols sous sorgho en monoculture (Tableau 6). En fonction de l'année, les augmentations des teneurs en $\mathrm{N}$ des sols a été de 4\% en 2013 et celles des teneurs en $\mathrm{N}$ et $\mathrm{P}$ des sols respectivement de 10 et $15 \%$ en 2014 .

En 2013, les teneurs en $\mathrm{N}$ et $\mathrm{P}$ des sols sous sorgho associé au niébé ont respectivement augmenté de 10 et $9 \%$ sous ZFN par rapport aux sols sous sorgho en monoculture (Tableau 6). Durant, cette même année, les teneurs en $\mathrm{P}$ des sols ont même été significativement réduites de $62 \%$ sous $\mathrm{ZS}$ et de $22 \%$ sous ZF sous sorgho associé au niébé comparativement aux sols sous sorgho en monoculture. En 2014, les teneurs en $\mathrm{N}$ des échantillons de sols prélevés sous sorgho associé au niébé comparées à ceux obtenus sous sorgho en monoculture ont été améliorées de $13 \%$ sous ZS, $6 \%$ sous ZF et $24 \%$ sous ZFP (Tableau 6). Cependant, c'est seulement sous ZFP que les teneurs en $\mathrm{P}$ des sols ont été augmentées sous sorgho associé au niébé par rapport aux sols prélevés sous sorgho en monoculture.

\section{Efficacité d'acquistion des nutriments du sorgho en association avec le niébé}

L'efficacité d'acquisition des nutriments par le sorgho ont été évaluées en construisant des droites de régressions linéaires entre les quantités de $\mathrm{N}$ et $\mathrm{P}$ acquis dans les grains de sorgho, les teneurs en $\mathrm{N}$ et $\mathrm{P}$ du sols sous sorgho associé au non au niébé, et les rendements du sorgho à la récolte (Figures 3 et 4). Cette efficacité est traduite par les valeurs des pentes des droites de régression linéaire et la significativité a été calculé selon le test de Tukey HSD $(\mathrm{p}<0,05)$.

Les régressions linéaires établies entre les rendements sorgho et les quantités en $\mathrm{N}$ et $\mathrm{P}$ des grains de sorgho montrent que les quantités en $\mathrm{N}$ et $\mathrm{P}$ des grains sont hautement et significativement corrélés aux rendements grains du sorgho associé ou non au niébé en
2013 et 2014 (Figure 3). En 2013, l'efficacité d'acquisition de l'azote pour contribuer à produire $1 \mathrm{t} \mathrm{ha}^{-1}$ de grains de sorgho a été de l'ordre de 1,29 $\pm 0,2 \mathrm{~g} \mathrm{~N} \mathrm{~g}^{-1}$ grains de sorgho associé au niébé contre $1,01 \pm 0,11 \mathrm{~g} \mathrm{~N} \mathrm{~g}^{-1}$ grains du sorgho en monoculture (Figure 3a). En 2014, cette valeur a été $1,69 \pm 0,15 \mathrm{~g} \mathrm{~N} \mathrm{~g}^{-1}$ grains pour contribuer à produire $1 \mathrm{t} \mathrm{ha}^{-1} \mathrm{de}$ grains de sorgho associé au niébé et de $1,01 \pm 0,22 \mathrm{~g} \mathrm{~N} \mathrm{~g}^{-1}$ grains pour la monoculture du sorgho (Figure 3b). En 2013, l'efficacité d'acquisition de $\mathrm{P}$ dans les grains afin de produire $1 \mathrm{t} \mathrm{ha}^{-1}$ de grains de sorgho a été de $1,01 \pm 0,12 \mathrm{~g}$ pour le sorgho associé au niébé contre $0,96 \pm 0,12 \mathrm{~g} \mathrm{P} \mathrm{g}^{-1}$ grains pour le sorgho en monoculture (Figure 3c). En 2014, l'efficacité a été de $1,05 \pm 0,04 \mathrm{~g} \mathrm{P} \mathrm{g}^{-1}$ grains pour le sorgho associé au niébé et de 1,09 $\pm 0,16$ $\mathrm{g} \mathrm{P} \mathrm{g}^{-1}$ grains pour le sorgho en monoculture (Figure 3d).

Les régressions linéaires entre les rendements du sorgho et les teneurs en $\mathrm{N}$ et $\mathrm{P}$ des sols prélevés pendant la récolte sont présentées dans la Figure 4. En 2013, les rendements grains du sorgho associé au niébé ont été corrélés aux teneurs en $\mathrm{N}$ et $\mathrm{P}$ des sols. Les rendements totaux grains de sorgho et de niébé ont été significativement corrélés $\left(\mathrm{R}^{2}=\right.$ 0,$20 ; \mathrm{p}=0,02$ ) aux teneurs en $\mathrm{N}$ des sols avec une efficacité d'acquisition de $\mathrm{N}$ des sols de $1,25 \pm 0,5 \mathrm{mg} \mathrm{N} \mathrm{g}^{-1}$ sol (Figure 4a). Les teneurs en $\mathrm{P}$ des sols sont hautement et significativement corrélées $\left(\mathrm{R}^{2}=0,45\right)$ aux rendements totaux grains du sorgho et de niébé (Figure 4b) ; aux rendements grains du sorgho associé au niébé $\left(\mathrm{R}^{2}=0,52\right)$ (Figure $4 \mathrm{c}$ ); aux quantités de $\mathrm{N}$ acquis par les grains de sorgho associé au niébé $\left(\mathrm{R}^{2}=0,50\right)$ (Figure $\left.4 \mathrm{~d}\right)$; et aux quantités de $\mathrm{P}$ acquis par les grains de sorgho associé au niébé $\left(\mathrm{R}^{2}=0,59\right.$ (Figure $4 \mathrm{e}$ ). En 2014, ce sont seulement les teneurs en N des sols qui ont été corrélées aux rendements en pailles du sorgho associé ou non au niébé avec des efficacités respectives de $0,88 \pm 0,26 \mathrm{mg} \mathrm{N}$ $\mathrm{g}^{-1}$ sol $\left(\mathrm{R}^{2}=0,31 ; \mathrm{p}=0,003\right)$ et de $1,87 \pm 0,72$ $\mathrm{mg} \mathrm{N} \mathrm{g}{ }^{-1} \operatorname{sol}\left(R^{2}=0,21 ; p=0,02\right)$ (Figure 4f). 
Tableau 2 : Effet global de l'association mixte sorgho-niébé sur les rendements des cultures.

\begin{tabular}{|c|c|c|c|c|c|}
\hline Effets & $\begin{array}{l}\text { Rendements } \\
\text { paille } \\
\left(\mathrm{t} \mathrm{ha}^{-1}\right)\end{array}$ & $\begin{array}{l}\text { Rendements } \\
\text { grains } \\
\left(\text { t ha }^{-1}\right)\end{array}$ & $\begin{array}{l}\text { N grains } \\
\left(\mathrm{g} \mathrm{g}^{-1}\right)\end{array}$ & $\begin{array}{l}\text { P grains } \\
\left(\mathrm{g} \mathrm{g}^{-1}\right)\end{array}$ & $\begin{array}{l}\text { Rendements totaux } \\
\text { grains de sorgho } \\
\text { et de niébé }\left(t \text { ha }^{-1}\right)\end{array}$ \\
\hline \multicolumn{6}{|c|}{ Mode de culture } \\
\hline SN & $1,68 \pm 1,42 \mathrm{a}$ & $0,47 \pm 0,66 \mathrm{a}$ & $0,41 \pm 0,33 \mathrm{a}$ & $0,31 \pm 0,47 \mathrm{a}$ & $0,89 \pm 0,64 b$ \\
\hline S & $2,20 \pm 1,91 \mathrm{a}$ & $0,64 \pm 0,61 \mathrm{a}$ & $0,41 \pm 0,53 \mathrm{a}$ & $0,47 \pm 0,49 \mathrm{a}$ & $0,64 \pm 0,60 \mathrm{a}$ \\
\hline $\mathbf{p}$ & $0,11 n s$ & $0,14 n s$ & $0,99 n s$ & $0,06 n s$ & $0,04 *$ \\
\hline \multicolumn{6}{|c|}{ Année*mode } \\
\hline \multicolumn{6}{|c|}{ De culture } \\
\hline \multicolumn{6}{|l|}{2013} \\
\hline SN & $2,78 \pm 1,91 \mathrm{a}$ & $0,85 \pm 0,61 \mathrm{a}$ & $0,76 \pm 0,53 \mathrm{a}$ & $0,53 \pm 0,49 a$ & $1,13 \pm 0,6 a$ \\
\hline $\mathrm{S}$ & $3,15 \pm 1,42 \mathrm{a}$ & $1,02 \pm 0,64 \mathrm{a}$ & $0,59 \pm 0,33 \mathrm{a}$ & $0,68 \pm 0,47 \mathrm{a}$ & $1,02 \pm 0,64 a$ \\
\hline $\begin{array}{l}\mathbf{p} \\
2014\end{array}$ & $0,42 n s$ & $0,32 n s$ & $0,15 n s$ & $0,26 \mathrm{~ns}$ & $0,38 n s$ \\
\hline SN & $0,59 \pm 0,49 a$ & $0,09 \pm 0,16 \mathrm{a}$ & $0,05 \pm 0,09 a$ & $0,09 \pm 0,16 \mathrm{a}$ & $0,63 \pm 0,34 b$ \\
\hline $\mathrm{S}$ & $1,25 \pm 0,96 b$ & $0,27 \pm 0,31 b$ & $0,23 \pm 0,23 b$ & $0,26 \pm 0,25 b$ & $0,27 \pm 0,31 \mathrm{a}$ \\
\hline p & $\mathbf{0 , 0 0 3} * *$ & $\mathbf{0 , 0 1 *}$ & $0,0004 * *$ & $0,004 * *$ & $\mathbf{0 , 0 0 2} * *$ \\
\hline
\end{tabular}

Tableau 3 : Effet de l'association mixte sorgho-niébé sur les rendements du sorgho en fonction de l'année et des traitements.

\begin{tabular}{|c|c|c|c|c|c|}
\hline Effets & $\begin{array}{l}\text { Rendements } \\
\text { pailles } \\
\left(\mathrm{t} \mathrm{ha} \mathbf{~}^{-1}\right) \\
\end{array}$ & $\begin{array}{l}\text { Rendements } \\
\text { grains } \\
\left(\mathbf{t ~ h a}^{-1}\right) \\
\end{array}$ & $\begin{array}{l}\text { N grains } \\
\left(\mathrm{g} \mathrm{g}^{-1}\right)\end{array}$ & $\begin{array}{l}\text { P grains } \\
\left(\mathrm{g} \mathrm{g}^{-1}\right)\end{array}$ & $\begin{array}{l}\text { Rendements totaux } \\
\text { grains de sorgho } \\
\text { et de niébé }\left(\mathrm{t} \text { ha }^{-1}\right)\end{array}$ \\
\hline \multicolumn{6}{|c|}{$\begin{array}{l}\text { Année*mode de culture } \\
\text { *Traitement } \\
2013\end{array}$} \\
\hline $\mathrm{ZS}(\mathrm{SN})$ & $1,52 \pm 1,10 \mathrm{a}$ & $0,50 \pm 0,57 \mathrm{a}$ & $0,50 \pm 0,50 \mathrm{a}$ & $0,33 \pm 0,36 \mathrm{a}$ & $0,69 \pm 0,52 \mathrm{a}$ \\
\hline ZS (S) & $2,05 \pm 1,35 a$ & $0,69 \pm 0,78 \mathrm{a}$ & $0,37 \pm 0,28 a$ & $0,43 \pm 0,4 \mathrm{a}$ & $0,68 \pm 0,78 \mathrm{a}$ \\
\hline $\mathbf{p}$ & 0,38ns & $0,57 \mathrm{~ns}$ & $0,5 \mathrm{~ns}$ & $0,58 \mathrm{~ns}$ & $0,99 n s$ \\
\hline $\mathrm{ZF}(\mathrm{SN})$ & $2,68 \pm 1,57 a$ & $0,88 \pm 0,67 \mathrm{a}$ & $0,77 \pm 0,47 a$ & $0,53 \pm 0,32 \mathrm{a}$ & $1,21 \pm 0,57 \mathrm{a}$ \\
\hline $\mathrm{ZF}(\mathrm{S})$ & $3,24 \pm 1,06 a$ & $0,95 \pm 0,56 \mathrm{a}$ & $0,60 \pm 0,31 \mathrm{a}$ & $0,66 \pm 0,35 a$ & $0,95 \pm 0,56 a$ \\
\hline $\mathbf{p}$ & $0,39 \mathrm{~ns}$ & $0,83 n s$ & $0,36 n s$ & $0,41 n s$ & $0,34 n s$ \\
\hline ZFN (SN) & $4,12 \pm 2,10 \mathrm{a}$ & $1,16 \pm 0,44 a$ & $1,02 \pm 0,55 a$ & $0,74 \pm 0,67 a$ & $1,49 \pm 0,43 a$ \\
\hline $\mathrm{ZFN}(\mathrm{S})$ & $4,16 \pm 1,03 a$ & $1,42 \pm 0,30 \mathrm{a}$ & $0,8 \pm 0,29 a$ & $0,94 \pm 0,53 \mathrm{a}$ & $1,42 \pm 0,3 \mathrm{a}$ \\
\hline $\mathbf{p}$ & $0,96 n s$ & $0,16 \mathrm{~ns}$ & $0,31 n s$ & $0,47 n s$ & $0,68 \mathrm{~ns}$ \\
\hline \multirow{2}{*}{\multicolumn{6}{|c|}{$\begin{array}{ll} & 2014 \\
\text { SN } & \end{array}$}} \\
\hline & & & & & \\
\hline $\mathrm{ZS}(\mathrm{SN})$ & $0,28 \pm 0,24 a$ & $0,01 \pm 0,03 \mathrm{a}$ & $0,01 \pm 0,02 \mathrm{a}$ & $0,01 \pm 0,02 \mathrm{a}$ & $0,46 \pm 0,38 b$ \\
\hline $\mathrm{ZS}(\mathrm{S})$ & $0,52 \pm 0,60 \mathrm{a}$ & $0,07 \pm 0,11 \mathrm{a}$ & $0,08 \pm 0,10 \mathrm{a}$ & $0,09 \pm 0,15 \mathrm{a}$ & $0,07 \pm 0,11 \mathrm{a}$ \\
\hline $\mathbf{p}$ & $0,27 n s$ & $0,12 n s$ & $0,07 n s$ & $0,12 n s$ & $\mathbf{0 , 0 1} *$ \\
\hline $\mathrm{ZF}(\mathrm{SN})$ & $0,76 \pm 0,52 a$ & $0,14 \pm 0,2$ & $0,07 \pm 0,10 \mathrm{a}$ & $0,13 \pm 0,19 a$ & $0,81 \pm 0,3 b$ \\
\hline $\mathrm{ZF}(\mathrm{S})$ & $1,41 \pm 0,79 a$ & $0,33 \pm 0,31$ & $0,24 \pm 0,19 b$ & $0,28 \pm 0,23 \mathrm{a}$ & $0,33 \pm 0,31 \mathrm{a}$ \\
\hline $\mathbf{p}$ & $0,06 n s$ & $0,14 n s$ & $\mathbf{0 , 0 3 n s}$ & $0,16 \mathrm{~ns}$ & $\mathbf{0 , 0 0 5} * *$ \\
\hline ZFP (SN) & $0,73 \pm 0,53 a$ & $0,12 \pm 0,19 a$ & $0,08 \pm 0,12 a$ & $0,13 \pm 0,18$ & $0,61 \pm 0,28 \mathrm{a}$ \\
\hline ZFP (S) & $1,81 \pm 1,02 b$ & $0,39 \pm 0,36 a$ & $0,38 \pm 0,26 b$ & $0,40 \pm 0,26$ & $0,39 \pm 0,36 \mathrm{a}$ \\
\hline p & $0,01 *$ & $0,06 \mathrm{~ns}$ & $0,006 * *$ & $\mathbf{0 , 0 2} *$ & $0,17 n s$ \\
\hline
\end{tabular}

SN = sorgho associé au niébé $; \mathrm{S}=$ monoculture du sorgho; $\mathrm{ZS}=$ zaï simple $; \mathrm{ZF}=$ zaï + substrats organiques $; \mathrm{ZFP}=$ zaï + substrats organiques + Burkina phosphate $; \mathrm{p}=$ probabilité selon l'analyse ANOVA des variances au seuil de $\alpha<5 \% ;$ Les moyennes et écarts types de la même colonne et affectées de la même lettre ne diffèrent pas significativement selon le test de Tukey au seuil de $5 \%$; $\mathrm{ns}=$ non significatif $; *=$ significatif $(\mathrm{p}<0,05) ; \quad * *=$ très significatif $(\mathrm{p} \leq 0,01) ; * * *=$ hautement significatif $(p \leq 0,001)$. 
Tableau 4 : LER partiel du sorgho associé au niébé par rapport au sorgho en culture pure.

\begin{tabular}{lll}
\hline Paramètres & $\begin{array}{l}\text { Rendements } \\
\text { paille }\left(\mathbf{t ~ h a}^{-1}\right)\end{array}$ & $\begin{array}{l}\text { Rendements } \\
\text { grains }\left(\mathbf{t ~ h a}^{-1}\right)\end{array}$ \\
\hline SN/S & 0,77 & 0,73 \\
SN/S (2013) & 0,88 & 0,83 \\
SN/S (2014) & 0,47 & 0,34 \\
& & \\
ZS(SN)/ZS(S) & 0,74 & 0,73 \\
ZF(SN)/ZF(S) & 0,83 & 0,93 \\
ZFN(SN)/ZFN(S) & 0,99 & 0,82 \\
& & \\
ZS(SN)/ZS(S) & 0,53 & 0,17 \\
ZF(SN)/ZF(S) & 0,54 & 0,42 \\
ZFP(SN)/ZFP(S) & 0,40 & 0,30 \\
SN = sorgho associé au niébé ; S = monoculture du sorgho; $\mathrm{ZS} \mathrm{=} \mathrm{zaï} \mathrm{simple} \mathrm{;} \mathrm{ZF} \mathrm{=} \mathrm{zaï} \mathrm{+} \mathrm{substrats} \mathrm{organiques} \mathrm{;} \mathrm{ZFP} \mathrm{=} \mathrm{zaï} \mathrm{+}$ \\
ubstrats organiques + Burkina phosphate.
\end{tabular}

Tableau 5 : Effet global de l'association mixte sorgho-niébé sur les teneurs en N, P des sols.

\begin{tabular}{lcc}
\hline Effets & $\mathbf{N}$ & $\mathbf{P}$ \\
& $\mathbf{m g ~ g}^{-1}$ sol & $\mathbf{m g ~ K}^{-1}$ sol \\
\hline Mode de culture & $0,75 \pm 0,27 \mathrm{a}$ & $9,60 \pm 7,84 \mathrm{a}$ \\
SN & $0,68 \pm 0,21 \mathrm{a}$ & $10,02 \pm 4,92 \mathrm{a}$ \\
$\mathrm{S}$ & $\mathbf{0 , 1 2 n s}$ & $\mathbf{0 , 7 4 n s}$ \\
$\mathbf{p}$ & & \\
\hline Année*mode de culture & & \\
2013 & $0,68 \pm 0,21 \mathrm{a}$ & $10,35 \pm 7,94 \mathrm{a}$ \\
SN & $0,66 \pm 0,18 \mathrm{a}$ & $11,97 \pm 3,24 \mathrm{a}$ \\
S & $\mathbf{0 , 6 6 n s}$ & $\mathbf{0 , 3 3 n s}$ \\
$\mathbf{p}$ & & \\
2014 & $0,82 \pm 0,31 \mathrm{a}$ & $8,84 \pm 7,80 \mathrm{a}$ \\
SN & $0,70 \pm 0,24 \mathrm{a}$ & $8,06 \pm 5,56 \mathrm{a}$ \\
S & $\mathbf{0 , 1 1 n s}$ & $\mathbf{0 , 6 7 n s}$ \\
$\mathbf{p}$ &
\end{tabular}

$\mathrm{SN}=$ sorgho associé au niébé $; \mathrm{S}=$ monoculture du sorgho; $\mathrm{ZS}=$ zaï simple $; \mathrm{ZF}=$ zaï + substrats organiques ; ZFP = zaï + substrats organiques + Burkina phosphate $; \mathrm{N}=$ azote total $; \mathrm{P}=$ Phosphore total $; \mathrm{p}=$ probabilité selon l'analyse ANOVA des variances au seuil de $\alpha<5 \%$; Les moyennes et les écarts types des moyennes de la même colonne et affectées de la même lettre ne diffèrent pas significativement selon le test de Tukey au seuil de 5\%; ns = non significatif. 
Tableau 6 : Effet de l'association mixte sorgho-niébé sur les teneurs en $\mathrm{N}$ et $\mathrm{P}$ des sols en fonction de l'année et des traitements.

\begin{tabular}{|c|c|c|}
\hline Effets & $\begin{array}{l}\mathrm{N} \\
\left(\mathrm{mg} \mathrm{g}^{-1} \text { sol) }\right.\end{array}$ & $\begin{array}{l}\text { P } \\
\left(\mathrm{mg} \mathrm{kg}^{-1} \text { sol) }\right.\end{array}$ \\
\hline \multicolumn{3}{|c|}{ Année *mode de culture*Traitement } \\
\hline $\mathrm{ZS}(\mathrm{SN})$ & $0,51 \pm 0,13 \mathrm{a}$ & $6,31 \pm 3,54 a$ \\
\hline $\mathrm{ZS}(\mathrm{S})$ & $0,51 \pm 0,15 \mathrm{a}$ & $10,19 \pm 2,22 b$ \\
\hline $\mathbf{p}$ & $0,95 \mathrm{~ns}$ & $0,01 *$ \\
\hline $\mathrm{ZF}(\mathrm{SN})$ & $0,73 \pm 0,21 \mathrm{a}$ & $10,47 \pm 7,92 \mathrm{a}$ \\
\hline $\mathrm{ZF}(\mathrm{S})$ & $0,74 \pm 0,16 \mathrm{a}$ & $12,75 \pm 3,56 a$ \\
\hline p & $0,88 \mathrm{~ns}$ & $0,44 n s$ \\
\hline ZFN (SN) & $0,80 \pm 0,20 \mathrm{a}$ & $14,27 \pm 9,71 \mathrm{a}$ \\
\hline ZFN (S) & $0,72 \pm 0,16 \mathrm{a}$ & $12,96 \pm 3,34 a$ \\
\hline p & $0,35 n s$ & $0,71 \mathrm{~ns}$ \\
\hline \multicolumn{3}{|c|}{2014} \\
\hline $\mathrm{ZS}(\mathrm{SN})$ & $0,56 \pm 0,18 \mathrm{a}$ & $7,08 \pm 7,33$ \\
\hline ZS (S) & $0,48 \pm 0,15 \mathrm{a}$ & $7,43 \pm 6,23$ \\
\hline p & 0,36 & $0,91 \mathrm{~ns}$ \\
\hline $\mathrm{ZF}(\mathrm{SN})$ & $0,88 \pm 0,11 \mathrm{a}$ & $7,55 \pm 4,24 \mathrm{a}$ \\
\hline $\mathrm{ZF}(\mathrm{S})$ & $0,83 \pm 0,22 \mathrm{a}$ & $8,10 \pm 2,76 a$ \\
\hline p & $0,56 \mathrm{~ns}$ & $0,74 \mathrm{~ns}$ \\
\hline ZFP(SN) & $1,02 \pm 0,37 \mathrm{a}$ & $11,90 \pm 10,50 a$ \\
\hline $\mathrm{ZFP}(\mathrm{S})$ & $0,77 \pm 0,17 \mathrm{a}$ & $8,66 \pm 7,29 a$ \\
\hline p & $0,09 \mathrm{~ns}$ & $0,45 n s$ \\
\hline
\end{tabular}

$\mathrm{SN}=$ sorgho associé au niébé $; \mathrm{S}=$ monoculture du sorgho $; \mathrm{ZS}=$ zaï simple $; \mathrm{ZF}=$ zaï + substrats organiques ; $\mathrm{ZFP}=$ zaï + substrats organiques + Burkina phosphate $; \mathrm{N}=$ azote total $; \mathrm{P}=$ Phosphore total $; \mathrm{p}=$ probabilité selon l'analyse ANOVA des variances au seuil de $\alpha<5 \%$. Les moyennes et les écarts types des de la même colonne, du même traitement et affectées de la même lettre ne diffèrent pas significativement selon le test de Tukey au seuil de $5 \% ; \mathrm{ns}=$ non significatif ; * $=$ significatif $(\mathrm{p}$ $<0,05)$.
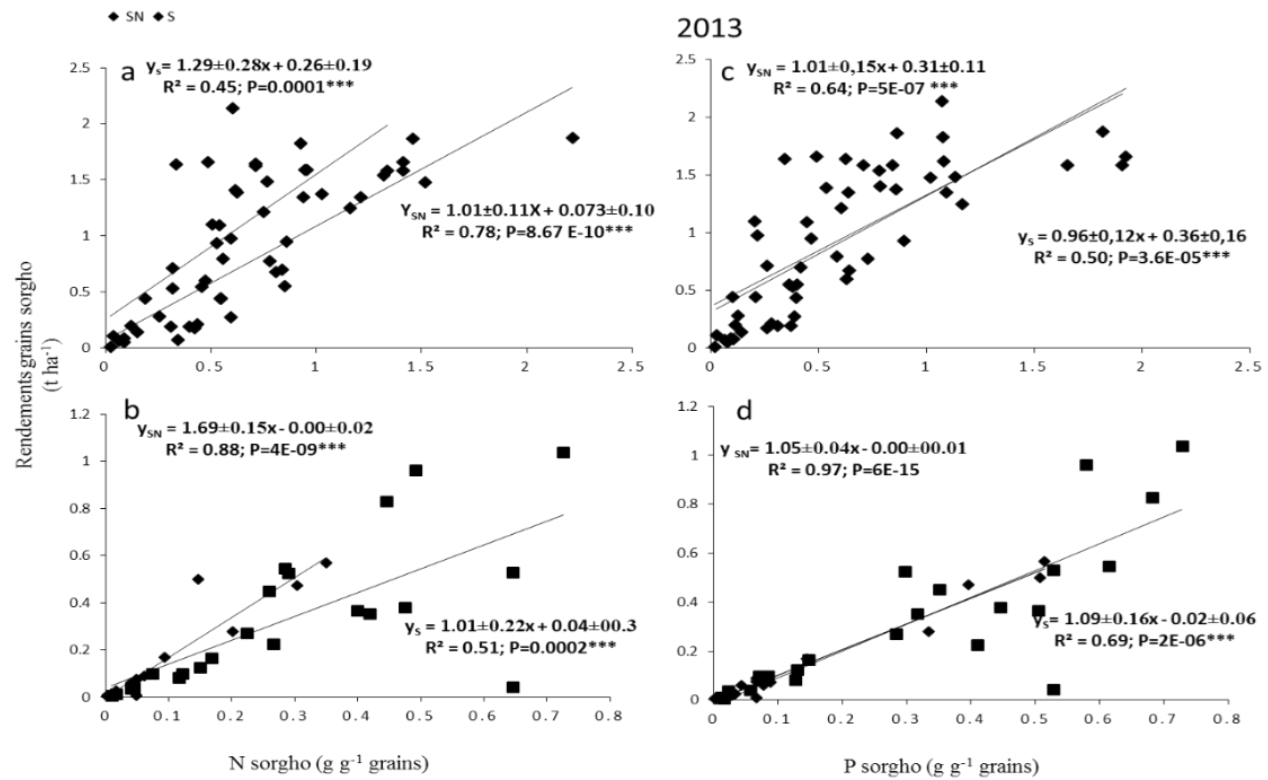

Figure 3 : Régression linéaire entre $\mathrm{N}$ et $\mathrm{P}$ acquis dans les grains et les rendements grains du sorgho en fonction des années.

$\mathrm{SN}=$ sorgho associé au niébé $; \mathrm{S}=$ monoculture du sorgho ; $\mathrm{N}=$ azote total $\mathrm{P}=$ Phosphore total $; \mathrm{p}=$ probabilité que cette régression soit significative selon le test de Pearson au seuil de $\alpha<5 \% ; *=$ significatif $(\mathrm{p}<0,05) ; * *=$ très significatif $(\mathrm{p} \leq$ $0,01) ; * * *=$ hautement significatif $(\mathrm{p} \leq 0,001)$. 

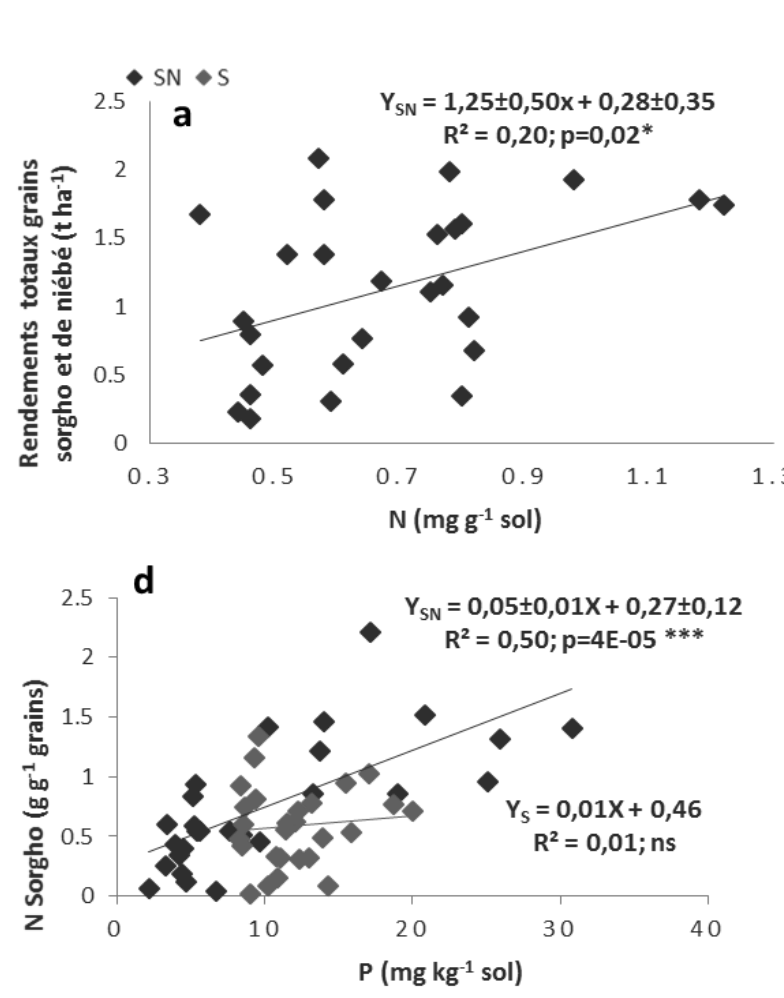

2013
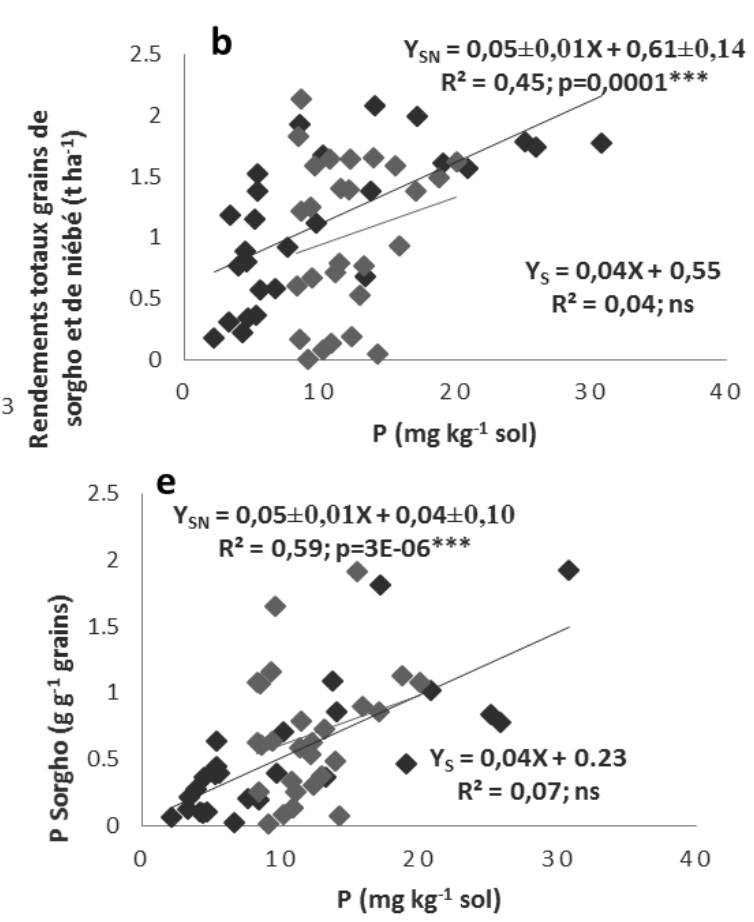
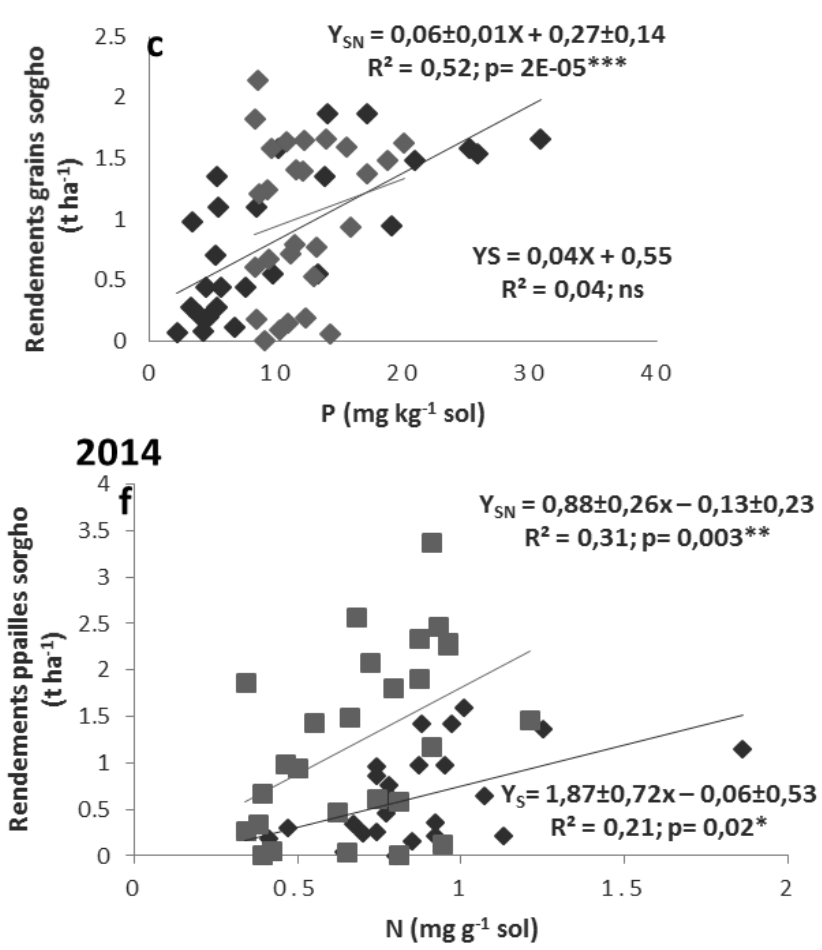

Figure 4 : Régression linéaire entre les rendements grains du sorgho et les paramètres chimiques en fonction des modes de culture et de l'année.

$\mathrm{SN}=$ sorgho associé au niébé $; \mathrm{S}=$ monoculture du sorgho; $\mathrm{N}=$ azote total $; \mathrm{P}=$ Phosphore total $; \mathrm{p}=$ probabilité que cette régression soit significative selon le test de Pearson au seuil de $\alpha<5 \% ;$ ns $=$ non significatif ; * = significatif $(\mathrm{p}<0,05) ; * *=$ très significatif $(\mathrm{p} \leq 0,01) ; * * *=$ hautement significatif $(\mathrm{p} \leq 0,001)$. 


\section{DISCUSSION}

Cette étude a été conduite dans l'optique d'apprécier la performance des associations mixtes sorgho-niébé sur la production du sorgho et la fertilité résiduelle des sols par rapport à la monoculture du sorgho en zone soudano-sahélienne du Burkina Faso. D'une manière générale, les résultats ont montré qu'aucune différence significative n'a été observée entre les rendements du sorgho en association mixte avec le niébé comparativement à ceux obtenus sous sorgho en monoculture et cela s'est justifié par des LER partiels du sorgho inférieur égal à 1 . Dans ce sens, des effets dépressifs pouvant aller jusqu'à $70 \%$ sur les rendements du sorgho associé au niébé par rapport au sorgho en monoculture avaient été constatés dans la savane du nord guinéenne du Nigéria par Tajudeen (2010) et dans le Sud-Est de Vienne en Autriche par Tauro et al. (2013). En effet, le manque de performance en termes de gains en rendements de sorgho associé au niébé comparativement au sorgho en monoculture serait imputable aux effets de compétitions dû aux modes d'associations mixtes et simultanées du sorgho et du niébé. A cet effet, il a été démontré que dans le système de culture intercalaire maïs-soja, la détermination du moment approprié de plantation du soja (durée de co-croissance) est l'un des facteurs les plus critiques pour réduire la concurrence entre les cultures associées permettant ainsi d'obtenir de meilleures rendements (Ahmed et al., 2020). Par contre, les rendements grains totaux de sorgho et de niébé (somme des rendements grains de sorgho et de niébé en culture associée) ont été globalement supérieurs aux rendements grains du sorgho en monoculture avec une augmentation significative en 2014 et un accroissement de $10 \%$ en 2013. Ces gains de rendements traduisent une performance relative et positive en termes de rendements des cultures associés mixtes sorgho-niébé par rapport à la monoculture du sorgho. Des augmentations globales de $+23 \%$ des quantités de $\mathrm{N}$ acquis dans les grains de sorgho associé au niébé par rapport à la monoculture du sorgho en 2013 corroborent les conclusions de Shivay et Singh (2000), Pal et Sheshu (2001) qui ont prouvé que les teneurs en $\mathrm{N}$ du maïs associé à une légumineuse étaient nettement améliorés contrairement à la monoculture. Cette augmentation pourrait être aussi le résultat d'une compétition de la légumineuse sur la céréale limitant ainsi la croissance de cette dernière tout en favorisant une concentration de l'azote dans les grains (Gooding et al., 2007). En effet, en culture mixte et simultanée sorgho-niébé, le niébé étouffe en quelque sorte les plantes de sorgho et réduit le nombre de pieds sur la parcelle. Cela permettrait aux pieds restant de sorgho d'accumuler de grande quantité d'azote résultant de l'offre du sol et de la décomposition des rhizodepôts du niébé. A contrario, en culture intercalaire avec le soja, les plantes de maïs ont accumulé des quantités plus faibles d'azote, de phosphore et de potassium par rapport à la monoculture du maïs en climat subtropical et humide de Yaan en Chine (Raza et al., 2020).

Durant les deux années de culture, les rendements totaux grains de sorgho et de niébé, les quantités de $\mathrm{N}$ acquises dans les grains de sorgho associé au niébé ont été fonctions de l'année mais aussi des traitements appliqués avec des performances plus prononcées sous ZS et ZF par rapport à ZFN et ZFP. Cela laisse alors transparaitre que l'association sorghoniébé reste plus performante dans des conditions de faibles apports d'azote et de phosphore au sol. Par ailleurs, les faibles acquisitions de $\mathrm{P}$ dans les grains de sorgho associé au niébé en comparaison à la monoculture du sorgho sont en phase avec les résultats de Musa et al. (2012) qui avaient montré que sous apport de $20 \mathrm{~kg} \mathrm{~N} \mathrm{ha}^{-1}$ ou 50 $\mathrm{kg}_{2} \mathrm{O}_{5}$ ha $^{-1}$ de triple superphosphate, le $\mathrm{P}$ des grains de sorgho associé au niébé a été bas par rapport à la monoculture du sorgho en zone de savane tropicale du Sud Est de Khartoum au Soudan.

Les augmentations globales et annuelles des teneurs en $\mathrm{N}$ des sols sous sorgho associé au niébé par rapport aux sols sous sorgho en monoculture montrent que la pratique des associations est relativement une source résiduelle d'azote pour les sols de la région. On note ainsi un effet synergique entre les gains en 
rendements totaux grains du niébé du sorgho, les quantités de $\mathrm{N}$ acquises dans les grains de sorgho associé au niébé et les teneurs en $\mathrm{N}$ des sols durant les deux années de culture. En effet, la complémentarité des légumineuses avec les céréales et leur capacité à fixer biologiquement l'azote de l'atmosphère contribue à l'amélioration de la fertilité des sols (Rusinamhodziet et al., 2012 ; Undie et al., 2012; Duvvada et Maitra, 2020). En 2013, c'est sous ZFN que les teneurs résiduelles en $\mathrm{N}$ et $\mathrm{P}$ des sols ont été respectivement améliorées sous sorgho associé au niébé comparativement à celles observées dans les sols sous sorgho en monoculture. En 2014, c'est sous ZFP que les teneurs en $\mathrm{N}$ et $\mathrm{P}$ des sols sous sorgho associé au niébé ont été les mieux augmentées par rapport aux sols de la monoculture du sorgho. Ces résultats montrent que la pratique des cultures associées sorgho-niébé a été plus performante en termes d'amélioration des teneurs résiduelles en $\mathrm{N}, \mathrm{P}$ par rapport à la monoculture du sorgho suite aux apports supplémentaires d'azote (ZFN) ou de phosphore (ZFP) aux substrats organiques. La disponibilité résiduelle de $\mathrm{N}$ et $\mathrm{P}$ des sols en culture mixte sorgho-niébé est fonction des quantités de $\mathrm{N}$ et $\mathrm{P}$ apportés par les traitements en sus des services de facilitation induite par le niébé. En phase avec nos résultats, les teneurs en $\mathrm{N}$ des sols ont été améliorées en culture intercalaire de maïs et de niébé sous apport de $50 \mathrm{~kg} \mathrm{~N} \mathrm{ha}{ }^{-1}$ comparativement à la monoculture du maïs dans le Sud-Est de l'Inde (Dahmardeh et al., 2010). A ce sujet, Laberge et al. (2011) estimaient à $20 \mathrm{~kg} \mathrm{ha}^{-1}$ un enrichissement de l'azote du sol par les rhizodépôts dans des associations mil-niébé au Niger. D'autres recherches avaient aussi rapporté une augmentation de la disponibilité de $\mathrm{P}$ inorganique dans la rhizosphère des légumineuses intercalées à des céréales ( $\mathrm{Li}$ et al., 2009 ; Latati et al., 2016) et serait la conséquence de l'acidification de la rhizosphère par les légumineuses, la respiration racinaire des nodules, l'exsudation des phosphatases, des carboxylates et/ou indirectement des activités microbiennes (Latati et al., 2016).
Les efficacités d'acquisition de $\mathrm{N}$ traduites par la valeur de la pente des droites de régression construites entre les rendements du sorgho et les quantités de $\mathrm{N}$ acquis dans les grains de sorgho associé au niébé ont été efficaces de $+22 \%$ en 2013 et de $+40 \%$ en 2014 comparativement à la monoculture du sorgho. Cela montre que l'association sorgho-niébé a efficacement utilisé l'azote disponible pour contribuer à une meilleure formation des grains $\mathrm{du}$ sorgho associé contrairement à la monoculture du sorgho. En 2013, les corrélations significatives entre les teneurs en $\mathrm{N}$ et $\mathrm{P}$ des sols et les rendements totaux grains de sorgho et de niébé ; et entre les teneurs en $\mathrm{P}$ des sols et les rendements grains, les quantités de $\mathrm{N}$ et $\mathrm{P}$ acquis dans les grains de sorgho associé au niébé contrairement à la monoculture du sorgho, traduit la performance de l'association sorgho-niébé en termes d'efficacité d'acquisition des nutriments du sol pour la formation des grains. Ainsi, cette performance dépend de l'efficacité qu'à l'association pour acquérir le $\mathrm{N}$ et le $\mathrm{P}$ des sols. La monoculture du sorgho a probablement été affectée par une faible efficacité d'utilisation des ressources (Chimono et al., 2016; Xue et al., 2016). Par ailleurs, les variations interannuelles des rendements du sorgho et de valeurs résiduelles des sols en éléments minéraux seraient imputables aux variations pluviométriques annuelles et aux compositions des substrats organiques annuellement utilisés. En effet, le cumul pluviométrique en 2014 a été de 20\% supérieur à celui enregistré en 2013 ce qui pourrait expliquer en partie la variation interannuelle des performances de rendements des cultures. Aussi, un même type de sol peut présenter des différences de potentiel de fertilité selon les conditions du climat local et les caractéristiques particulières de l'année considérée affectant les variations intra et interannuelles des productions des cultures.

\section{Conclusion}

L'étude conduite dans la région Nord du Burkina aux conditions pédo-climatiques précaires pour les productions agricoles a relevé que les pratiques locales d'associations mixtes sorgho-niébé sont moins performantes 
pour améliorer les rendements du sorgho associé au niébé comparé à la monoculture du sorgho. Par contre, l'association sorgho-niébé a été positivement performante en termes de gains de rendements totaux grains de sorgho et de niébé, d'acquisition de l'azote dans les grains de sorgho comparativement à la monoculture du sorgho. Les meilleures performances ont été obtenues sous zaï sans aucun apport et sous zaï associé aux substrats organiques locaux. L'association sorgho niébé a positivement amélioré les teneurs en $\mathrm{N}$ des sols en fonction de l'année de culture et des traitements. La fertilité résiduelle des sols sous sorgho associé au niébé comparativement à la monoculture du sorgho a été obtenue avec des apports supplémentaires de phosphore et d'urée aux substrats organiques. Ainsi, pour mieux identifier la pratique la plus performante à recommander, il s'avère nécessaire de comparer les processus rhizosphériques des pratiques culturales du sorgho associé ou non au niébé, la dynamique de croissance de ces deux espèces et de quantifier l'azote fixé par le niébé afin de mieux cerner les actions synergiques et antagonistes expliquant la performance de chaque pratique.

\section{CONFLIT D'INTERETS}

Tous les auteurs ainsi leurs organismes de tutelle ont pris connaissance de la version soumise du manuscrit et ont donné leur accord pour soumission. Les auteurs déclarent qu'ils n'ont aucun conflit d'intérêts.

\section{CONTRIBUTIONS DES AUTEURS}

KFZ est le principal instigateur de l'étude. EH a contribué à améliorer les qualités scientifiques et rédactionnelles du document. BTM et DG ont contribué efficacement à l'amendement du document.

\section{REMERCIEMENTS}

Ce travail a été supporté par le grand projet fédérateur FABATOPIMED, financé par la Fondation Agropolis, et le LMI-IESOL, financé par l'IRD. Les auteurs témoignent donc leur reconnaissance à ces deux institutions.

\section{REFERENCES}

Ahmed S, Raza MA, Yuan X, Yuan X, Du Y, Iqbal N, Chachar Q, Soomro A, Ibrahim F, Hussain S, Wang X, Weiguo L. 2020. Optimized planting time and co-growth duration reduce the yield difference between intercropped and sole soybean by enhancing soybean resilience toward size-asymmetric competition. Food Energy Secur., 9(3): e226. DOI: https://doi.org/10.1002/fes3.226

Aminifar J, Ghanbari A. 2014. Biological Facilitative Interactions and Their Roles on Maximize Growth and Productivity of Crops in Intercropping Systems. Scientia Agriculturae, 2(2): 90-95.

Aune JB, Bationo A. 2008. Agricultural intensification in the Sahel: the ladder approach. Agr. Syst., 98: 119-125. DOI: 10.1016/j.afgsy.2008.05.002

Bado BV, Bationo A, Cescas MP. 2006. Assessment of cowpea and groundnut contributions to soil fertility and succeeding sorghum yields in the Guinean savannah zone of Burkina Faso (West Africa). Biol. Fertil. Soils, 43: 171176.

DOI: http://dx.doi.org/10.1007/s00374-0060076-7

Bambara D, Zoundi JS, Tiendrébéogo JP. 2008. Association céréale/légumineuse et intégration agriculture-élevage en zone soudano-sahélienne. Cahiers Agricultures, 17(3): 297-301. DOI: https://doi.org/10.1684/agr.2008.0203

Bationo A, Sivakumar MVK, Acheampong K, Harmsen K. 1998. Technologies de lutte contre la degradation des terres dans la zone soudano-sahelienne de l'Afrique de l'Ouest. In L'Intensification Agricole au Sahel, Breman H, Sissoko K (éds). Karthala: Paris; 709-725.

Chimonyo VGP, Modi AT, Mabhaudhi T. 2016. Simulating yield and water use of a sorghum-cowpea intercrop using APSIM. Agric. Water Manag., 177: 317328. DOI: 10.1016/j.agwat.2016.08.021

$\mathrm{Cu}$ STT, Hutson J, Schuller KA. 2005. Mixed culture of wheat (Triticum aestivum L.) with white lupin (Lupinus albus L.) improves the growth and phosphorus 
nutrition of the wheat. Plant Soil, 272: 143-151. DOI: 10.1007/s11104-0044336-8

Dabat MH, Lahmar R, Guissou R. 2012. La culture du niébé au Burkina Faso : une voie d'adaptation de la petite agriculture à son environnement? ». Autrepart, 62: 95114.

DOI: https://doi.org/10.3917/autr.062.0095

Dabin B. 1967. Sur une méthode d'analyse du phosphore dans les sols tropicaux. Colloque sur la fertilité des Sols Tropicaux (19-25 Nov.), Tananarive, 99115.

Dahmardeh M, Ghanbari A, Syahsar BA, Ramrodi M. 2010. The role of intercropping maize (Zea mays L.) and Cowpea (Vigna unguiculata L.) on yield and soil chemical properties. African Journal of Agricultural Research, 5: 631636. DOI: 10.5897/AJAR09.607

Dakora FD, Aboyinga RA, Mahama Y, Alesaku J. 1987. Assessment of N2 fixation of legumes in groundnut (Arachis hypogea L.) and cowpea (Vigna unguiculata $\mathrm{L}$. Walp.) and their relative $\mathrm{N}$ contribution to a succeeding maize crop in northern Ghana. Mircen. J. Appl. Microb., 3: 389-399. DOI: 10.1007/BF00935697

Duvvada SK, Maitra S. 2020. Sorghum-based intercropping system for agricultural sustainability. Indian Journal of Natural Sciences, 10(60): 20306-20313.

Egbe OM, Egbo CU. 2011. Nodulation, nitrogen fixation and harvest index of extra-short-and short-duration cowpea varieties intercropped with maize at Otobi, Benue state, Nigeria. J. Anim. Plant Sci., 10: 1315-1324. DOI: https://www.m.elewa.org/JAPS/2011/10. $3 / 1$

Egesa AO, Njagi SN, Muui CW. 2016. Effect of facilitative interaction of sorghumcowpea intercrop on sorghum growth rate and yields. Journal of Environmental \& Agricultural Sciences, 9: 50-58. DOI: http://www.agropublishers.com/files/JE AS-09-50-58

FAO (Food and Agriculture Organization), 2000. La Base de données mondiale sur les sols: avantages et faiblesses pour la connaissance et l'utilisation des milieux édaphiques au Burkina Faso. Quatorzième réunion du sous-comité Ouest et Centre Africain de corrélation des sols pour la mise en valeur des terres. Abomey, Benin, 121-128.

FAO (Food and Agriculture Organization), 2009. Informations agricoles par pays. FAO Reports, Rome. http://www.fao.org/isfp/information-parpays/burkina-faso/fr/

FAO (Food and Agriculture Organization), 2014. IUSS Working Group WRB. 2014. World Reference Base for Soil Resources 2014. International soil classification system for naming soils and creating legends for soil maps. FAO World Soil Resources Reports, Rome, 191 p.

Fustec J, Corre-Hellou G. 2009. Les associations annuelles céréalesprotéagineux : quels potentiels agronomique et environnemental? Colloque régional d'Agriculture et de Biodiversité, Burkina Faso, pp. 11-14.

Fustec J, Lesuffleur F, Mahieu S, Cliquet JB. 2010. Nitrogen rhizodeposition of legumes. A review. Agronomy for Sustainable Development, 30(1): 57-66. https://hal.archivesouvertes.fr/file/index/docid/886487/filen ame/hal-00886487.pdf

Fustec J, Fabien L, Mahieu S, Cliquet JB. 2011. Rhizodéposition azote des légumineuses. Agriculture Durable, 2: 869-881. DOI: 10.1007/978-94-007-0394-0_38

Gooding MJ, Kasynova E, Ruske RE, Hauggaard-Nielsen H, Jensen ES, Dahlmann C, von Fragstein und Niemsdorff P, Dibet A, Corre-Hellou G, Crozat Y, Pristeri A, Romeo M, Monti M, Launay M. 2007. Intercropping with pulses to concentrate nitrogen and sulphur in wheat. J. Agric. Sci., 145: 469479.

DOI: https://doi.org/10.1017/S0021859607007 241

Jones DL, Nguyen C, Finlay RD. 2009. Carbon flow in the rhizosphere: carbon trading at the soil-root interface. Plant and Soil, 321(1-2): $5-33 . \quad$ DOI: 
https://doi.org/10.1007/s11104-0099925-0

Kitson RE, Mellon MG. 1944. Colorimetric Determination of Phosphorus as Molybdivanadophosphoric Acid. Ind. Eng. Chem. Anal. Ed., 16: 379-383.

Laberge G, Haussmann BIG, Ambus P, Jensen HH. 2011. Cowpea $\mathrm{N}$ rhizodeposition and its below-ground transfer to a co-existing and to a subsequent millet crop on a sandy soil of the Sudano-Sahelian eco-zone. Plant Soil, 340(1-2): 369-382. DOI: https://doi.org/10.1007/s11104-0100609-6

Legwaila GM, Otshubile T, Mathowa T. 2019. Witness Mojeremane Effects of intercropping on the performance of sorghum (cv Segaolane) and cowpeas in Botswana. International Journal of Biosciences, 14(1): 444-453. DOI: 10.12692/ijb/14.1.444-453

Latati M, Bargaz A, Belarbi B, Lazali M, Benlahrech S, Tellaha S, Kaci G, Drevon JJ, Ounane SM. 2016. The intercropping common bean with maize improves the rhizobial efficiency, resource use and grain yield under low phosphorus availability. Eur J Agron., 72: 80-90. DOI: 10.1016/j.eja.2015.09.015

Li L, Shen J, Zhang F, Clairotte M, Drevon JJ, Le Cadre E, Hinsinger P. 2008. Dynamics of phosphorus fractions in the rhizosphere of common bean (Phaseolus vulgaris L.) and durum wheat (Triticum turgidum durum L.) grown in monocropping and intercropping systems. Plant Soil, 312: 139-150.

https://www.researchgate.net/publication /304544051

Li YY, Yu C, Cheng X, Li CJ, Sun JH, Zhang FS, Lambers H, Li L. 2009. Intercropping alleviates the inhibitory effect of $\mathrm{N}$ fertilization on nodulation and symbiotic N2 fixation of faba bean. Plant Soil, 323: 295-308. DOI: 10.1007/s11104-0099938-8

Liu L, Wang YF, Yan XW, Li JW, Jiao NY, $\mathrm{Hu}$ SJ. 2017. Biochar amendments increase the yield advantage of legumebased intercropping systems over monoculture. Agriculture, Ecosystem and
Environment, 237: 16-23. DOI: $10.1016 /$ j.agee.2016.12.026

Makoi JHJR. 2009. Seed flavonoid concentration in cowpea genotypes and the effect of plant density on growth, N2 fixation and rhizosphere phosphatases and grain yield of cowpea intercropped with sorghum. Ph.D. Thesis, Faculty of Applied Science, Cape Peninsula University of Technology, Peninsula, 158 p.

Mayer J, Buegger F, Jensen E, Schloter M, Hess J. 2003. Residual nitrogen contribution from grain legumes to succeeding wheat and rape and related microbial process. Plant Soil, 255: 541554. DOI: $10.1023 / \mathrm{A}: 1026081015076$

Mead R, Willey RW.1980. The Concept of a "Land Equivalent Ratio" and Advantages in Yields from Intercropping. Experimental Agriculture, 16: 217-228. DOI:

http://dx.doi.org/10.1017/S00144797000 10978

Musa EM, Elsheikh EAE, Ahmed IAM, Babiker EE. 2012. Intercropping Sorghum (Sorghum bicolor L.) and Cowpea (Vigna unguiculata L.): Effect of Bradyrhizobium Inoculation and fertilization on minerals Composition of sorghum seeds. Agronomy, 18: 1-9. DOI: $10.5402 / 2012 / 356183$

Olsen SR, Cole CV, Watanabe FS, Dean LA. 1954. Estimation of Available Phosphorus in Soils by Extraction With Sodium Bicarbonate (ed). U.S. Dept. of Agriculture: USA.

Ouédraogo S. 2005. Intensification de l'agriculture dans le plateau central du Burkina Faso : une analyse des possibilités à partir des nouvelles technologies. Thèse de Doctorat, Rijks Universiteit, Groningen, 2005.

Pal UR, Sheshu Y. 2001. Direct and residual contribution of symbiotic nitrogen fixation by legumes to the yield and nitrogen uptake of maize (Zea mays L.) in the Nigerian Savannah. J. Agron. and Crop Sci., 187: 53-58. DOI: 10.1046/j.1439-037X.2001.00482.x 
Rahman MM, Amano T, Shiraiwa T. 2009. Nitrogen use efficiency and recovery from $\mathrm{N}$ fertilizer under ricebased cropping systems. Aust. J. Crop. Sci., 3: 336-351.

Raza MA, Feng LY, van der Werf W, Iqbal N, Khan I, Mohi Ud, Din A, Naeem M, Meraj Tehseen, Hassan M, Khan A, Lu F, Xin L, Ahmed M, Yang F, Zhang J, Khan A. 2020.Optimum strip width increases dry matter, nutrient accumulation, and seed yield of intercrops under the relay intercropping system. Food Energy Secur., 1(1): 1-14. DOI: https://doi.org/10.1002/fes3.199

Rusinamhodzi L, Marc C, Justice N, Giller K. 2012. Maize-grain legume intercropping is an attractive option for ecological intensification that reduces climatic risk for smallholder farmers in central Mozambique. Field Crops Research, 136: 12-22. DOI: 10.1016/j.fcr.2012.07.014

Tajudeen OO. 2010. Evaluation of SorghumCowpea Intercrop Productivity in Savanna Agro-ecology using Competition Indices. Journal of Agricultural Science, 2(3). DOI:10.5539/jas.v2n3p229

Undie UL, Uwah DF, Attoe EE. 2012. Effect of Intercropping and Crop Arrangement on Yield and Productivity of Late Season Maize/soybean Mixtures in the Humid Environment of South Southern Nigeria. Journal of Agricultural Science, 4(4): 116. DOI:10.5539/jas.v4n4p37

Tauro TP, Adu-Gyamfi J, Dhliwayo DKC, Heng LK. 2013. Nitrogen and phosphorus budgets for sorghum and cowpea production under simulated sole-and intercropping systems in low-and medium-P soils. African J. Agric., 8: 727735. DOI: $10.5897 / A J A R 11.494$

Wichern F, Eberhardt E, Mayer J, Joergensen RG, Müller T. 2008. Nitrogen rhizodeposition in agricultural crops: Methods, estimates and future prospects. Soil Biol Biochem., 40: 30-48. DOI: 10.1016/j.soilbio.2007.08.010

Willey RW. 1979. Intercropping its important and research needs: competition and yield advantages. Field Crop Abstracts, 32: 110.

Xiao Y, Li L, Zhang F. 2004. Effect of root contact on interspecific competition and $\mathrm{N}$ transfer between wheat and fababean using direct and indirect $15 \mathrm{~N}$ techniques. Plant Soil, 262: 45-54. DOI: 10.1023/B:PLSO.0000037019.34719.0d

Xue Y, Xia H, Christie P, Zhang Z, Li L, Tang C. 2016. Crop acquisition of phosphorus, iron and zinc from soil in cereal/legume intercropping systems: a critical review. Ann. Bot., 117(3): 363-377. DOI: 10.1093/aob/mcv182

Zongo KF, Traoré M, Hien E, Blavet D, Clermont-Dauphin C, Drevon JJ. 2017. Variability of cowpea (Vigna unguiculata L.) nodulation: what efficiency in use of the rhizobial symbiosis for plant growth under zaï cultivation in Sub-Saharan agro-ecosystem of Burkina Faso? I.J.C.A.R., 6(03): 2759-2767. DOI: 10.24327/ijcar.2017.2767.0100

Zongo KF. 2017. Déterminants des performances des associations céréaleslégumineuses dans les agroécosystèmes soudano-sahéliens du Burkina Faso. Thèse de Doctorat, Université Ouaga I Pr Joseph KI-ZERBO, Burkina Faso, 186 p. www.secheresse.info/spip.php?article70 079

Zongo KF, Hien E, Drevon JJ, Blavet D, Masse D, Clermont-Dauphin C. 2016. Typologie et logique socio-économique des systèmes de culture associant céréales et légumineuses dans les agro-écosystèmes Soudano-Sahéliens du Burkina Faso. Int. J. Biol. Chem. Sci., 10(1): 290-312. DOI: 10.4314/ijbcs.v10i1.12 